\title{
Implementation of an Al ready BACS system in Treviso school with DCV (Demand Control Ventilation)
}

\author{
Massimiliano Magri ${ }^{1 *}$, Francesco Padovan ${ }^{1}$, Fabio Fabris $^{2}$, and Sandro Michelin ${ }^{3}$ \\ ${ }^{1}$ Coster Group s.r.l., via San G.B. de La Salle,4/a - 20132 Milan, Italy \\ ${ }^{2}$ Province of Treviso, Italy \\ ${ }^{3}$ Province of Treviso. Former studio DEA progetti, Italy
}

\begin{abstract}
The pandemic has highlighted the extreme importance of indoor air quality (IAQ). Especially in schools, so places that have always been critical for the spread of highly contagious viral diseases, IAQ is an increasingly necessary need. In the province of Treviso, a tailored system has been installed: there are both winter and summer air conditioning, plus AHU's capable of guaranteeing the necessary air exchange to obtain a healthy level of the air inside the classrooms. The county also intends to replicate this experience in all schools of its territory and monitor the operation of these plants continuously. The important matter is not only to implement systems equipped with HRV (heat recovery ventilation), but also to equip them with automation and control systems capable of implementing an high automation standard according to EN 15232-1 and a high SRI or Smart Readiness Indicator defined by the EPBD III directive 844/2018. A high index ensures an implementation of a distributed intelligence system all over the plant, connected to the cloud and capable of extrapolating the physical variables, then processing them with ML (machine learning) and AI (artificial intelligence) techniques optimized for the HVAC algorithms. At the end, it is not enough to detect quantities such as EI (environmental index) but it is also necessary to process the data for the purposes of predictive maintenance and much more.
\end{abstract}

\section{Introduction}

The pandemic has indelibly marked our lives and the approach to the design of air conditioning systems, focusing on the quality of the air. As is well known, we spend $90 \%$ of our time inside the buildings where we live, work, study, etc. Before the pandemic, the issue of air quality was not so acute, so the few people who had the foresight to think about it before, now find themselves ahead of the others.

In this case we are talking about the far-sighted foresight of Eng. Fabio Fabris and Eng. Sandro Michielin of the Province of Treviso, who were grappling with the expansion of an

\footnotetext{
* Corresponding author: Massimiliano.Magri@costergroup.eu
} 
agricultural technical institute in which an additional part of 14 classrooms has been built. The systems were designed through the most current methods (BIM) considering both air conditioning and lighting, but above all the quality of the environments at a time when COVID had not yet arrived in Italy.

What then fully realized the futuristic vision of the Province and its designers in this plant is the adoption of controllers based on a truly innovative visual programming system and even more than the adoption of a BMS based on the Haystack system. Through this system it is possible to combine BMS in the field with high-level software such as cloud Computing, Machine Learning and artificial intelligence.

\section{Expansion of sartor institute}

As shown in figure 1, the expansion of the State Institute of Secondary Education called "SARTOR INSTITUTE" located in the Municipality of Castelfranco Veneto, via Postioma di Salvarosa, 28, consists in the construction of a new body of $\mathrm{n} .14$ classrooms and related toilets, inside the complex.

The school complex already includes the following buildings:

-Body A Ex Convitto, in which they find accommodations of the classrooms, a boiler room and the kitchen of the school canteen;

-Body B Gym for use by the Institute;

-Body C School Building Agricultural Building Sartor, with classrooms and administration;

The following floor plan shows both the existing buildings and the inclusion of the new school extension covered by this intervention

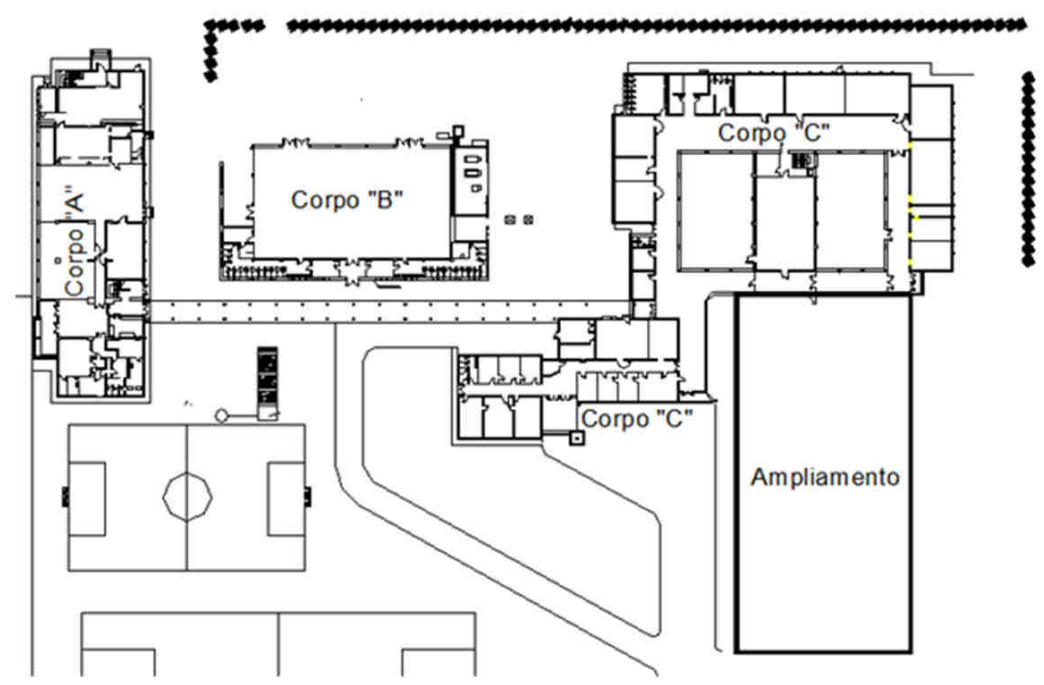

Fig. 1. Enlargement plan 


\section{Air conditioning system}

The thermal system aims to perform mainly the winter conditioning of the new rooms constituting the expansion of the school complex and guarantees:

- heating of all environments in winter;

- supply energy to the coils of heat recovery devices.

It is also planned to operate the plant in cooling regime for the period of the midseasons, approximately 15 April-15 June and 15 September-15 October, in order to guarantee better comfort of the occupants in case situations of thermal accumulations arise inside the classrooms due to the high crowding.

The thermal power required for the new plant was determined on the basis of the project data resulting from the calculation of the values of winter thermal dispersion (Law 10/91) and subsequent D.P.R. and UNI EN standards (Annex 2).

The heating system as a whole is mainly composed of:

- $\quad \mathrm{N}^{\circ} 1$ reversible water/water type heat pump with condensation by geothermal probes;

- $\quad \mathrm{N}^{\circ} 14$ mechanical ventilation units with heat recovery/free-cooling, one for each classroom, for primary air treatment;

- $\quad \mathrm{N}^{\circ} 4$ secondary circuits starting from the supply manifold divided as follows:

- ventilation unit circuit;

- circuit plant radiant ceiling classrooms east wing;

- circuit system radiant ceiling classrooms west wing;

○ radiant floor system circuit corridors and toilets;

- $\mathrm{N}^{\circ} 1$ circuit plant geothermal probes.

- $\mathrm{N}^{\circ} 1$ dedicated heat pump to produce DHW

The emission system in the room will consist of radiant ceiling panels inside the classrooms and radiant floor panels in the corridors and inside the toilets.

\section{Main features related to the heating conditioning system}

- Location: CASTELFRANCO VENETO (TV)

- Type: SECONDARY SCHOOL

- Gross heated surface: $1316 \mathrm{~m}^{2}$

- Gross heated volume: $6716.91 \mathrm{~m}^{2}$

- Number of floors above ground: 1

- Number of classrooms: 14

- Other managed rooms: 2 separate toilet blocks by gender, 14 total toilet rooms of which 2 are specific for people with disabilities

- Capacity number of pupils at full capacity: 420 Total pupils (30 pupils per classroom)

- Total subdivision of plant areas: 4 circuits

- Degrees day Municipality of Castelfranco Veneto referring to the 2019/2020 season: 2497 Degrees day

\section{Main reference values used}

-Primary ventilation system flow rate: $800 \mathrm{~m}^{3} / \mathrm{h}$ for each individual machine

-Replacement max primary air classrooms: $5 \mathrm{Vol} / \mathrm{h}$

-Standard classroom project rate: $800 \mathrm{~m}^{3} / \mathrm{h}$ 
-Min air flow per classroom: $530 \mathrm{~m}^{3} / \mathrm{h}$

-Air flow rooms accessories: $350 \mathrm{~m}^{3} / \mathrm{h}$ air extraction for each toilet block

-Heat Pump thermal power for ambient air conditioning: $105.4 \mathrm{~kW}$

-Heat pump thermal power dedicated for DHW production: $0.8 \mathrm{~kW}+1.2 \mathrm{~kW}$ electrical resistance integration

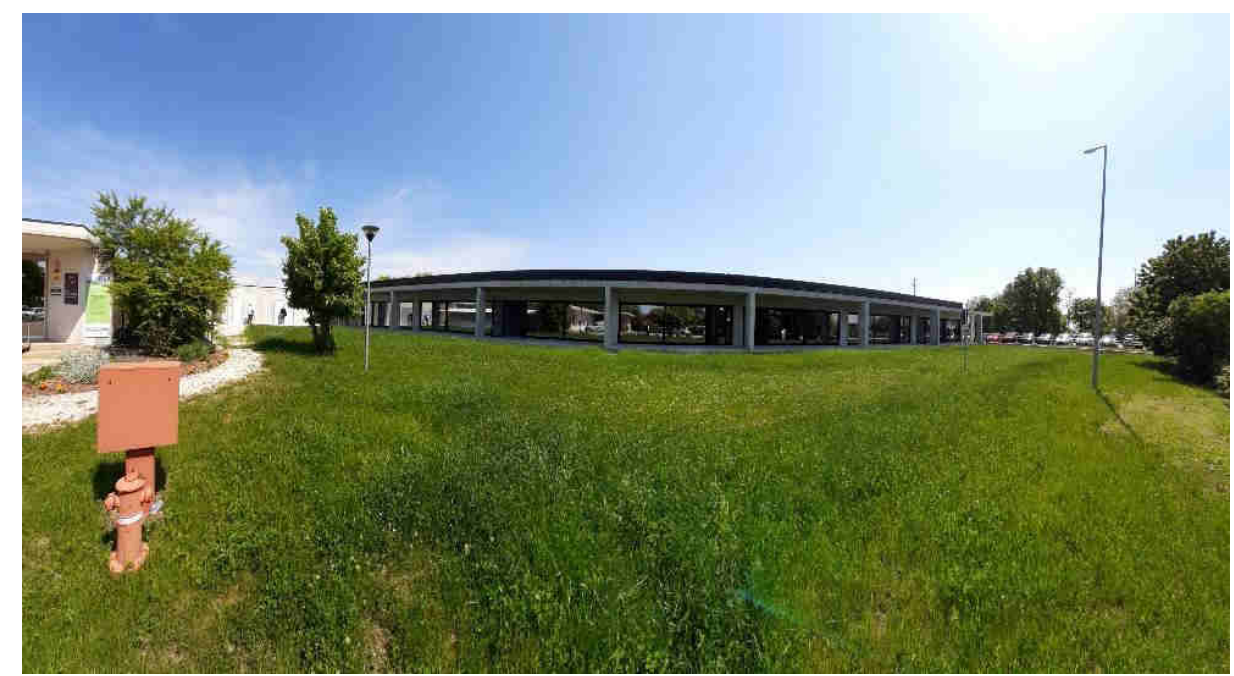

Fig. 2. Image of the new extension part of the school

\subsection{The school project}

The province has a role to play in an innovative design approach, but it should actually be normal nowadays. In fact, the enlarged property is an NZEB (EPC in Annex 1) even if the obligation starts only from 1.1.2021. The generation of the heat transfer fluid is ensured by a geothermal heat pump powered by a photovoltaic plant. The heating is ceiling panels with DCV for single classroom, latest generation fixtures and LED lighting. Let's analyze deeper the aspects.

\subsection{The building and the structures}

The province The enlarged portion of the building is structured as follows:

- Very low thermal transmittance coating $-0.182 \mathrm{~W} /\left(\mathrm{m}^{2} \mathrm{~K}\right)$

- Windows fixtures $-\max 1.4 \mathrm{~W} /\left(\mathrm{m}^{2} \mathrm{~K}\right)$

All data are in the technical report Italian Law 10/91 in annex 2.

The outside of the classrooms is shaded by the extension of the ceiling. 


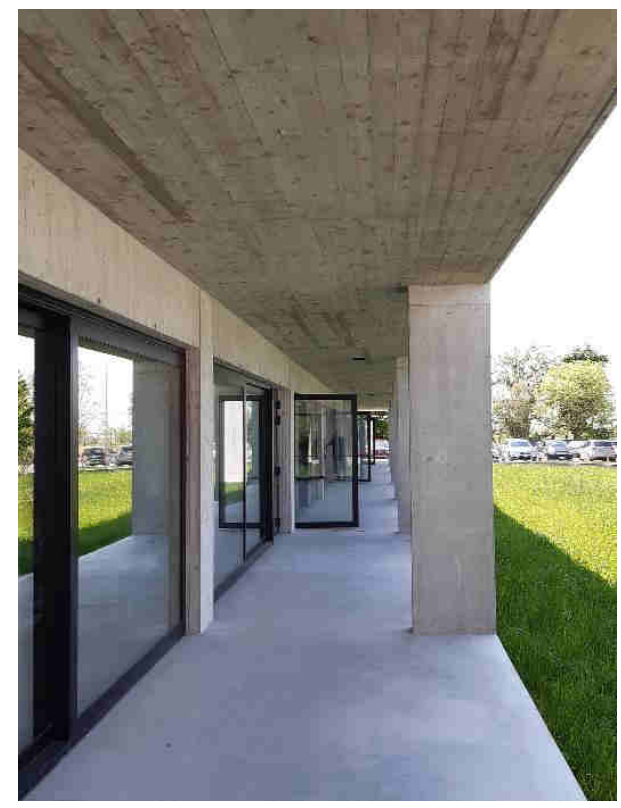

Fig. 3. Outside hallway beside the classrooms, to allow shading

In this way solar radiation is used for heating since the sun is low in winter, instead during the summer, when the sun is high, the radiation is interrupted thanks to the extra ceiling. Being a school, summer use is limited and summer radiation can affect only during the early morning hours. 


\subsection{Part of the plant}

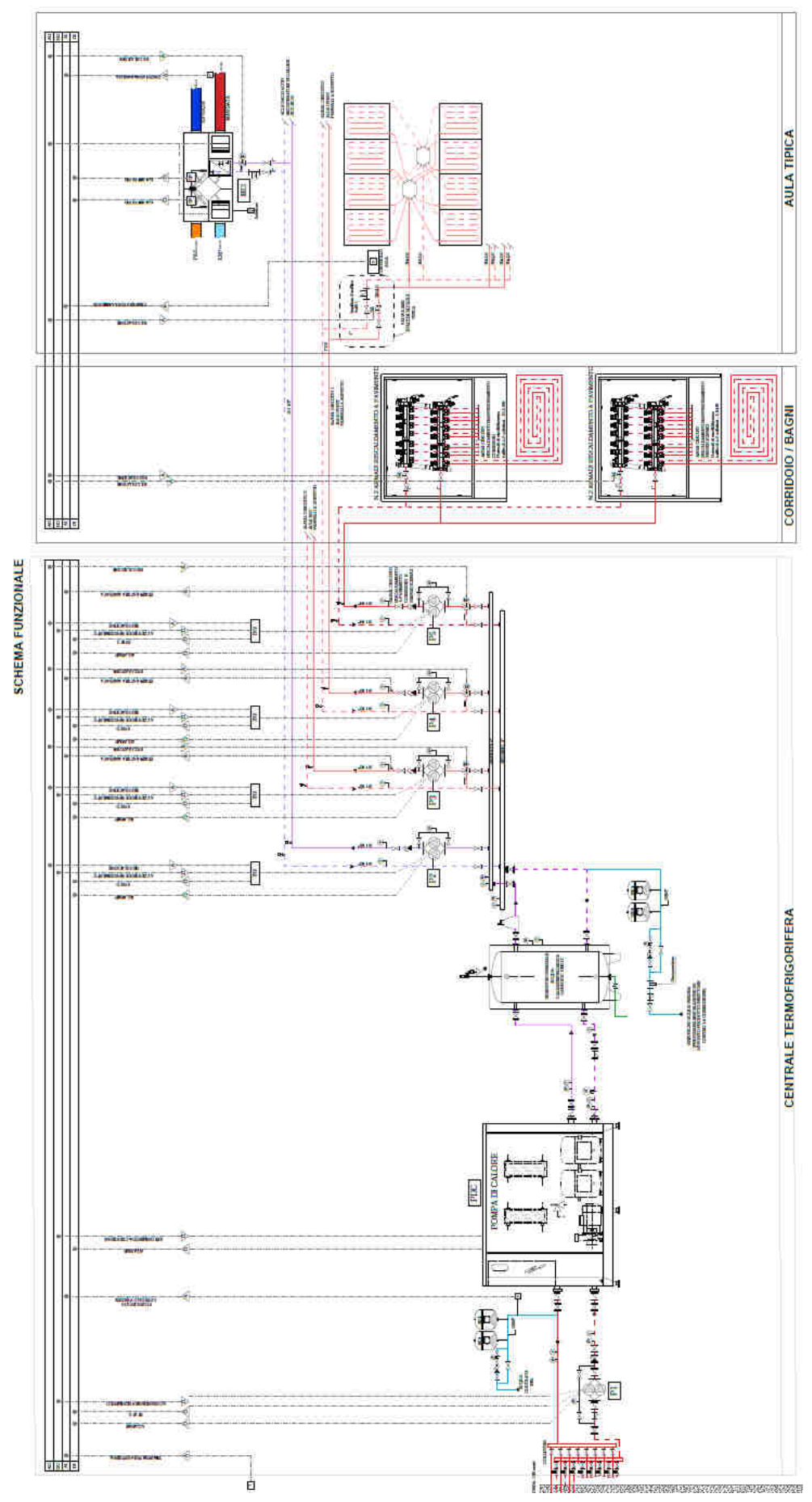

Fig. 4. Diagram of the entire Sartor plant 


\subsubsection{Classroom}

Each classroom is designed to:

1. Hydronic air conditioning with radiant ceiling panels

2. DCV with heat recovery and hot/cold post coil

3. Temperature probes, relative humidity and $\mathrm{CO}_{2}$

Winter and summer air conditioning is ensured by ceiling panels with interception valve controlled by the area controller.

The DCV is made through an AHU dedicated to each classroom equipped with

- fans to inverter $0-10 \mathrm{~V}$

- high-yield heat recovery

- post coil

- dampers

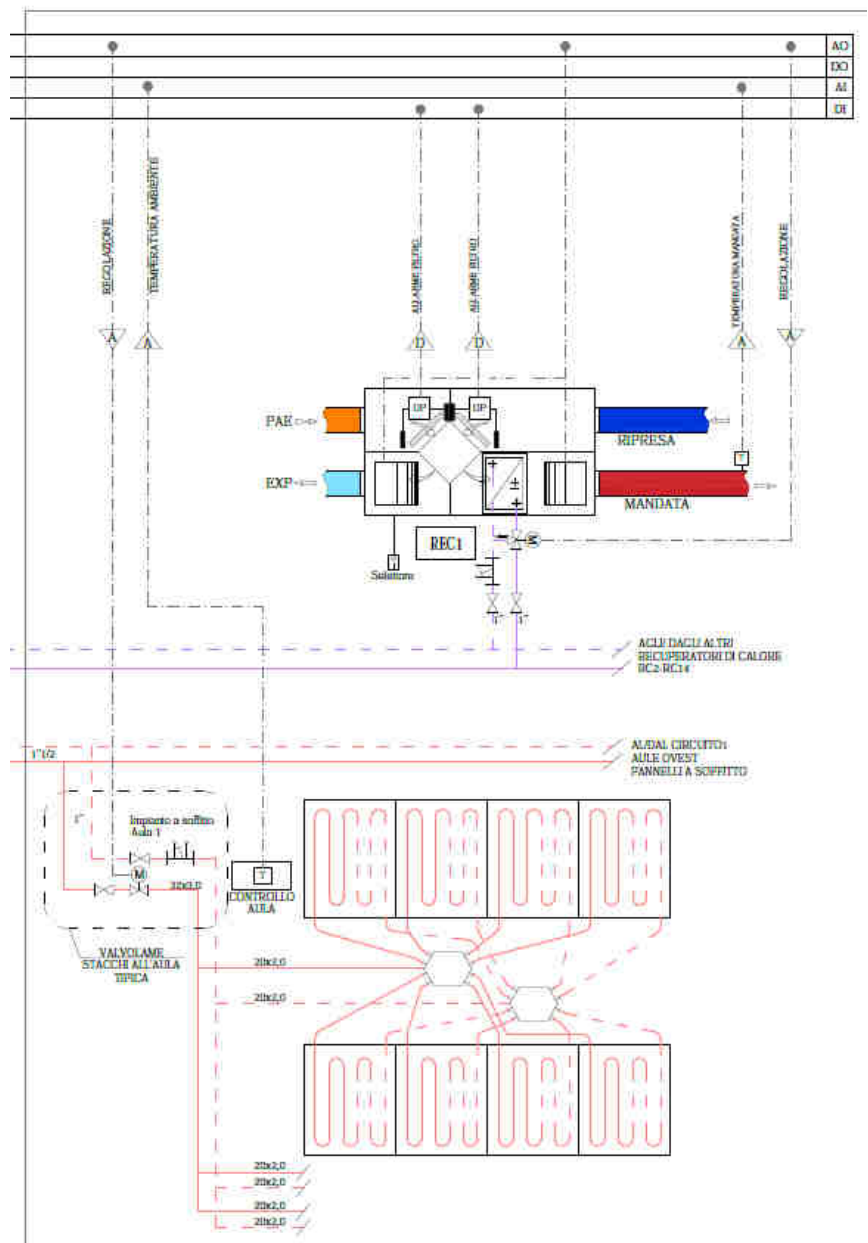

Fig. 5. Diagram of a classroom

The presence of the DCV is far from obvious because the design of the technology started before the COVID-19 emergency. This means that the Province of Treviso had already taken into account the 
problem of air quality at a time when many did not care about the problem. This will be discussed in the next section

\subsubsection{The distribution}

The hydraulic circuit consists of a two-tube manifold with these deliveries:

- for the AHU post batteries of the DCV of the classrooms

- mixed for the East classroom panels

- mixed for West classroom panels

- mixed for corridor panels and hygienic services

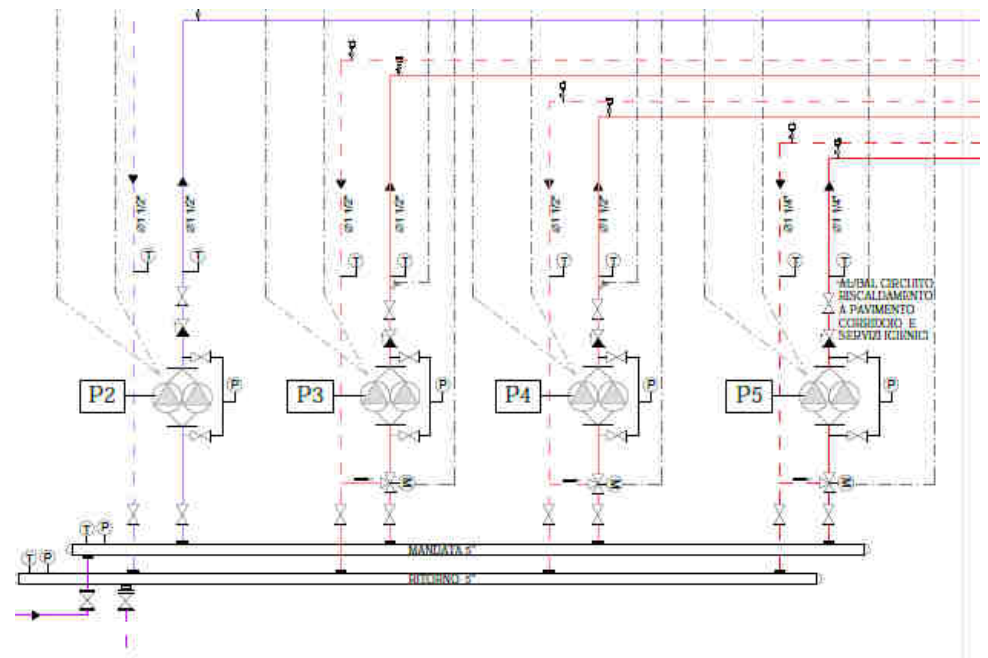

Fig. 6. Delivery Schema

\subsubsection{Production}

Hot/cold production is ensured by a heat pump with geothermal probes, $105.4 \mathrm{~kW}$ power, COP 3.61

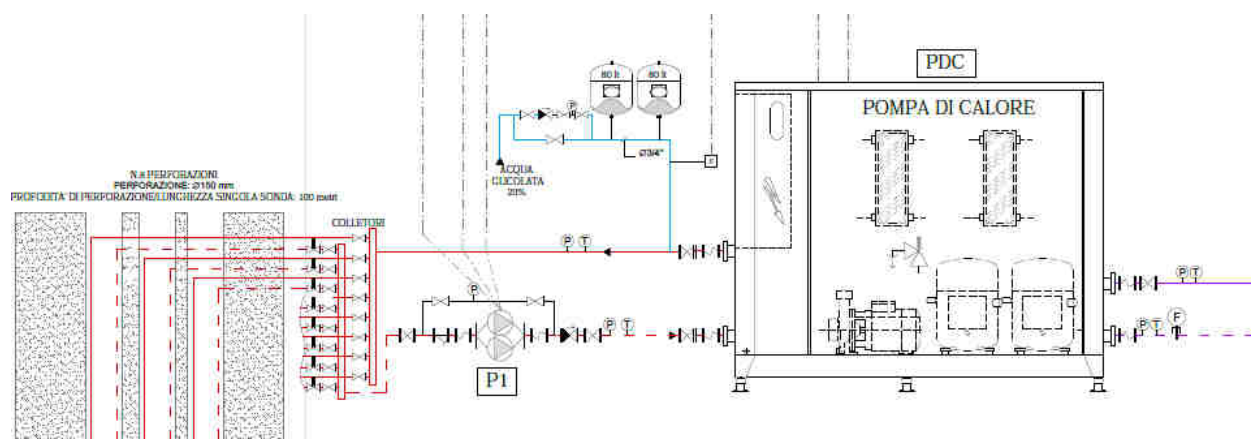

Fig. 7. Diagram of hot/cold production via geothermal HP 


\subsubsection{Production The photovolitaic fielb}

A photovoltaic field has been installed in the roof using photovoltaic cell modules in polycrystalline silicon with a nominal power of $30.8 \mathrm{~kW}$.

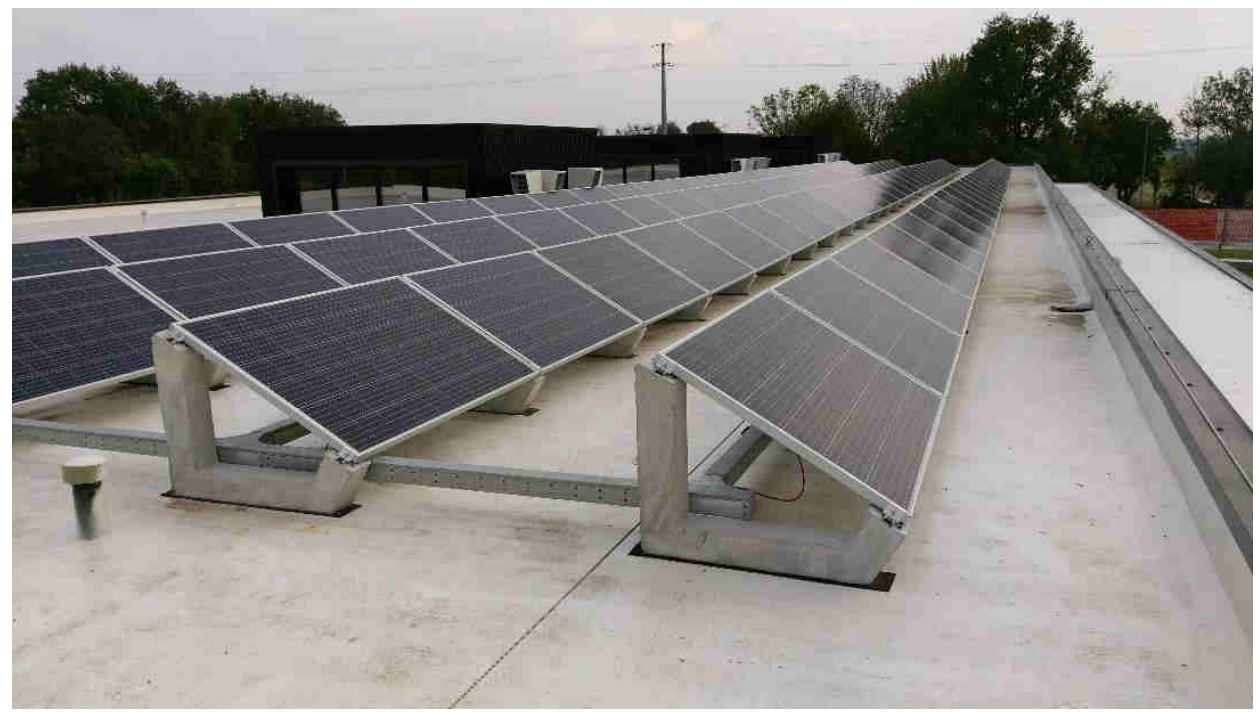

Fig. 8. 30kW PV field

\subsubsection{Control}

Control is one of the most important parts for the efficiency of the whole system while ensuring the correct parameters of comfort and healthiness of the rooms.

A programmable hardware was used with an innovative system for simplicity and immediacy. Such a system is a CAD that allows a normal thermotechnical operator to make programs for PLC without having any preparation of programming languages. To program, in fact, it is enough:

- open the programming software

- click on the add icon of a form marked with a green "+"

- choose the form you want by using the gear icon

- configure the form that you chose

These simple steps result in:

- Plc programming files with any I/O modules needed to manage all the points to be controlled

- Scada screenshot 


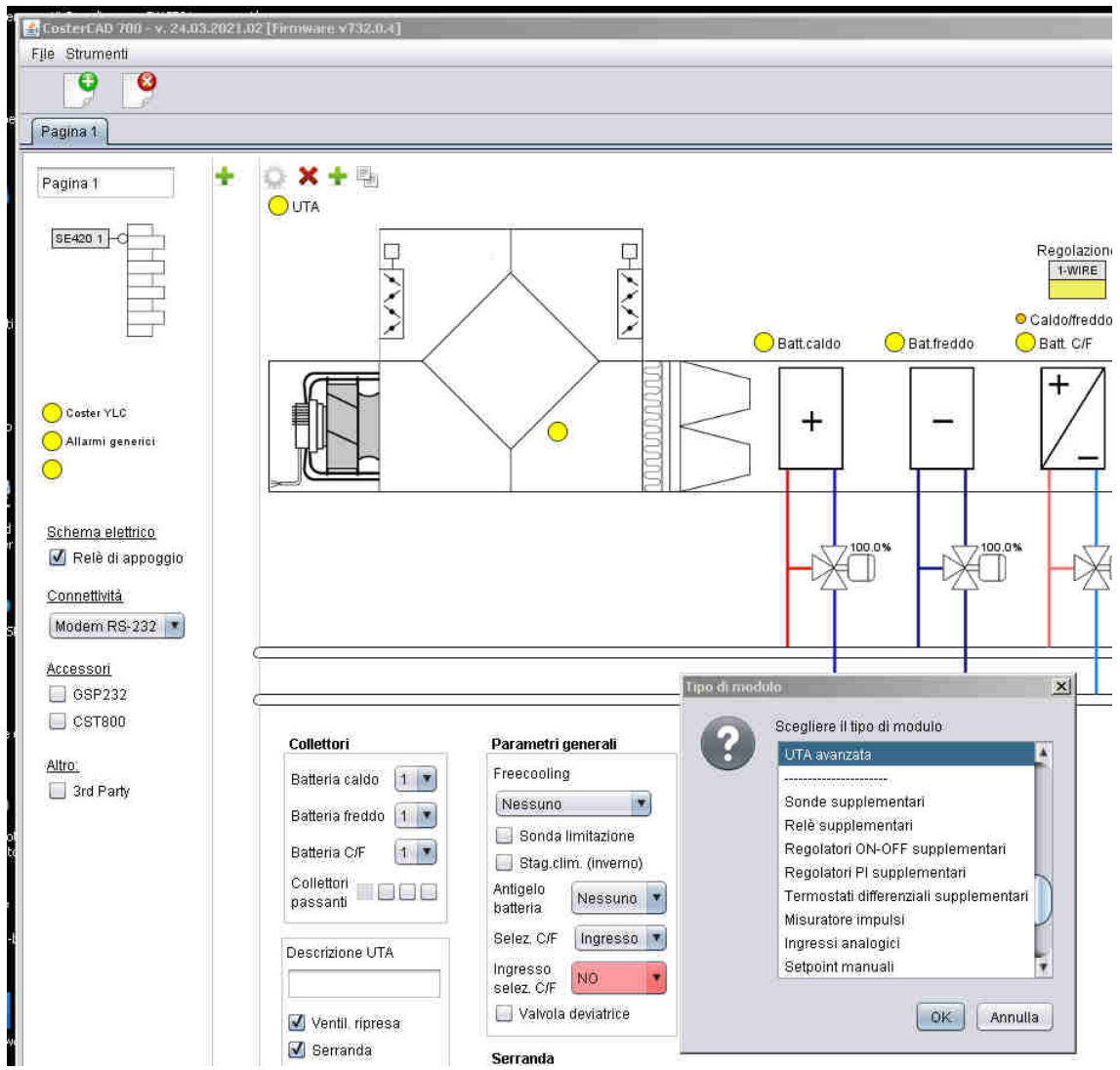

Fig. 9. An example of PLC CAD programming of a complete AHU.

In the classrooms, the controlled parameters are:

- temperature

- relative humidity

- air quality in terms of $\mathrm{CO}_{2}$ concentration

The most interesting part is related to air quality, which denotes a top-down aeraulic circuit, having vents directed towards the windows and the air recovery done in the opposite side of the classroom, at the bottom. In this way any viral charges and other pathogens are directed down and the probability of contagion is reduced 


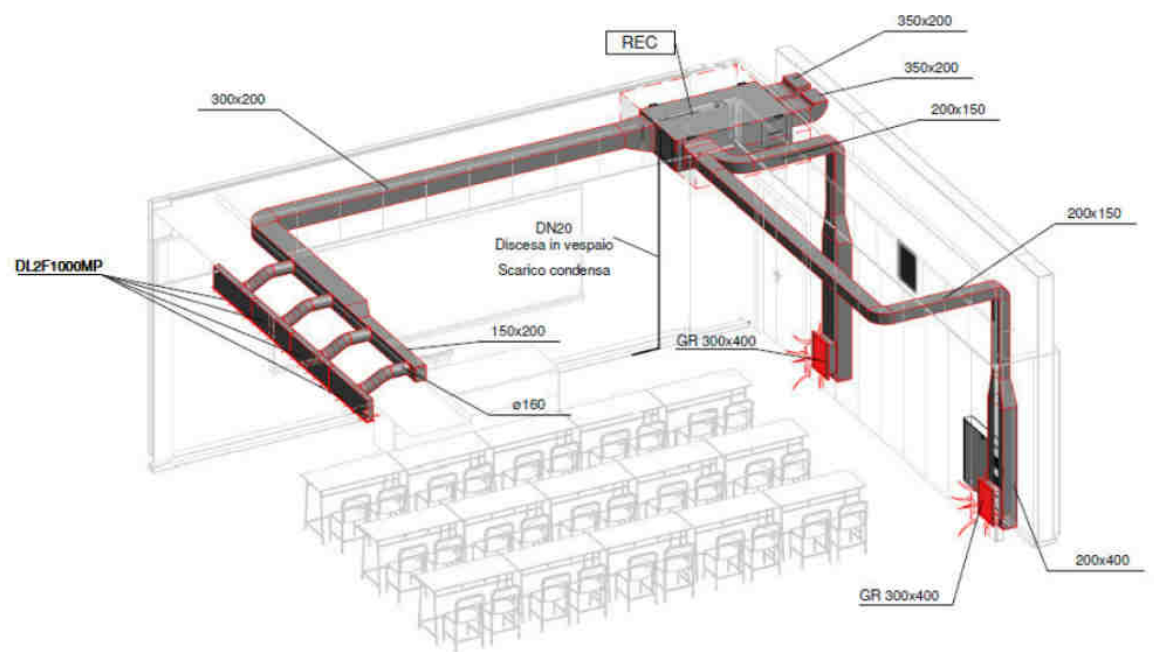

Fig. 10. Aeraulic diagram of a classroom made with BIM technology.

The regulation was placed near the AHU and accessible by inspection hatch

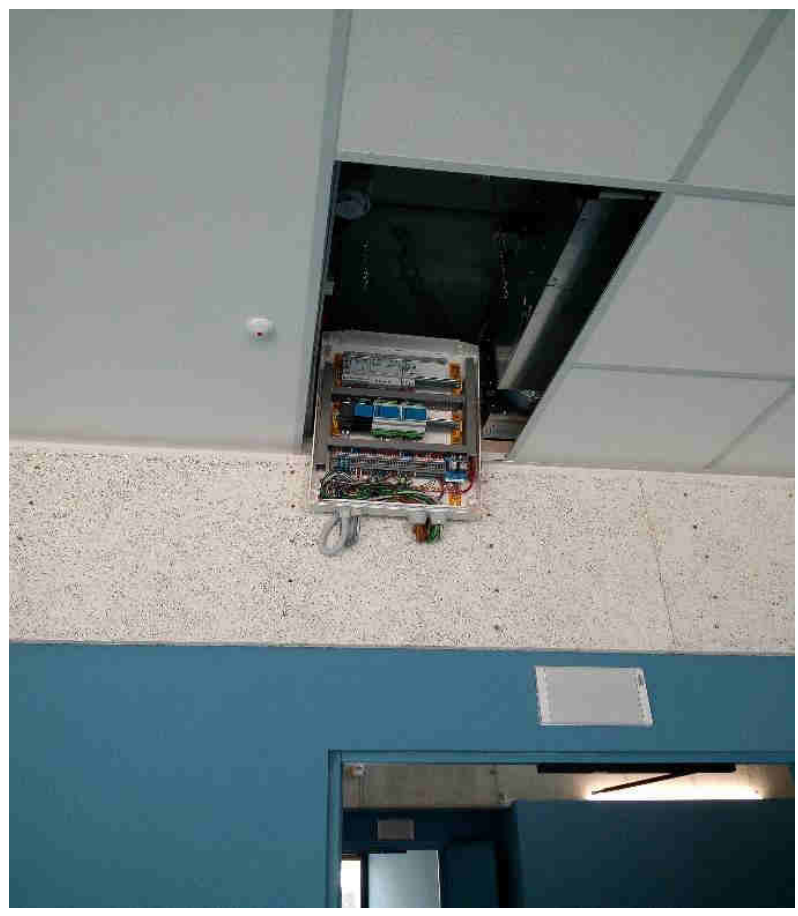

Fig. 11. The AHU adjustment panel of the class.

The temperature regulation logic is achieved through on-off valves with proportional regulation and setpoints according to a time schedule. Room temperature fluctuations are minimal but are greatly affected by the endogenous heat developed by the pupils present. 


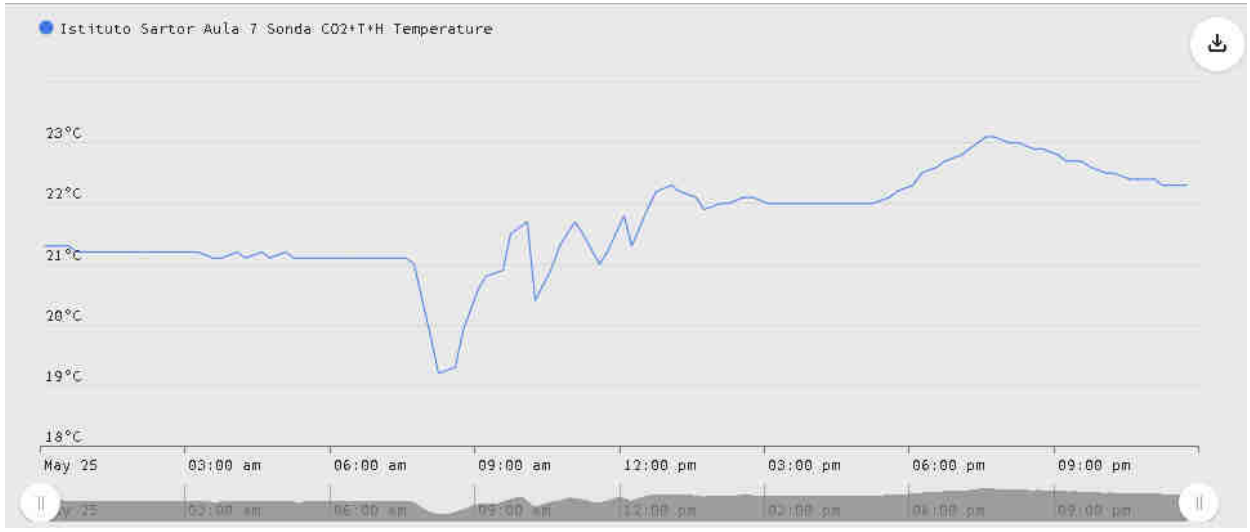

Fig. 12. Classroom temperature logger

The most interesting regulation is done on IAQ. In fact, depending on the concentration of $\mathrm{CO}_{2}$, typically $1000 \mathrm{ppm}$, the controller acts on the speed of the AHU fan. The probes are connected in ModBus to the management system called "WEBGARAGE" which communicates the information to the field regulation system always through ModBus.

The $\mathrm{CO}_{2}$ quantity analyses carried out on May the $4 \mathrm{~h}$ this year certified the correct functionality of the system.

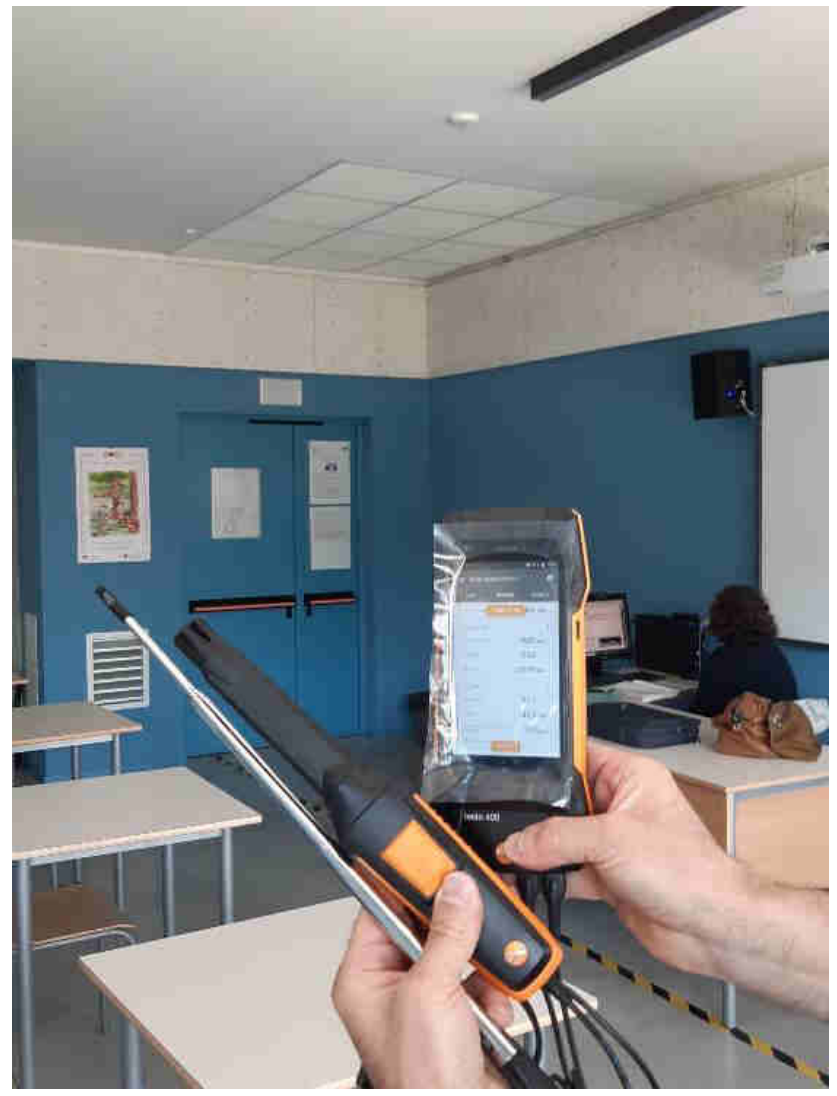

Fig. 13. IAQ Analysis 
The air terminal regulation in the environment determines the adjustment in the central plant and the distribution in a perspective EN 15232-1 [1] ensures that the demand signals generate just the power necessary for the heat generator and the exact flow rate to the distribution pumps.

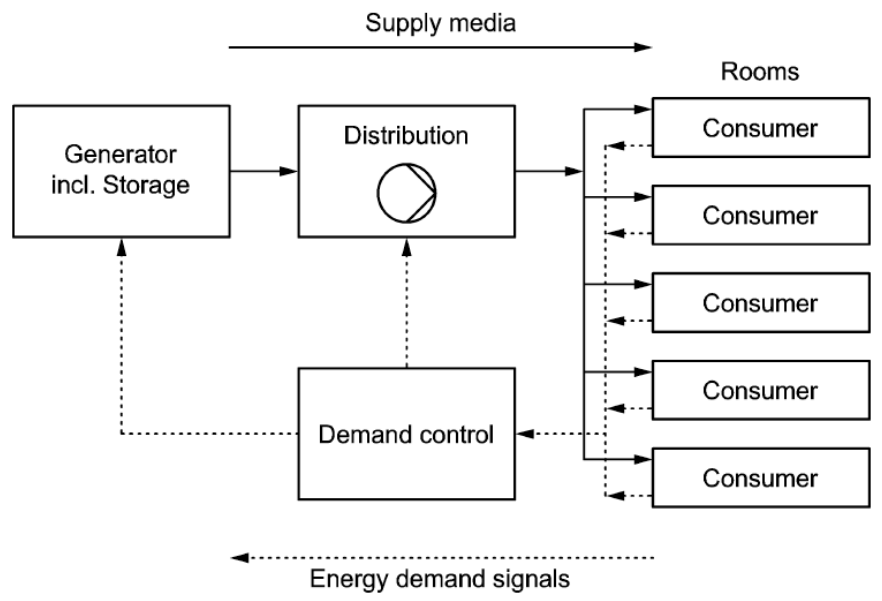

Fig. 14. Treatment of energy demand signals. Source: [1]

The setpoint of the heat pump is determined by the demand of the AHU post coils, while the heat panels are governed through climatic curves.

\subsubsection{Scada}

The architecture of the BMS system is structured with:

- $\quad$ RS 485 MODBUS backbone for T, $\mathrm{H} \%$ and $\mathrm{CO}_{2}$ environment probes

- RS 484 MODBUS backbone for YLC880 regulators

- Under backbone RS 485 per I/O expander

- IP Ethernet backbone

- Operator panel with BUILT-IN SCADA WEBGARAGE

- router IP GSM 4G to allow web control 


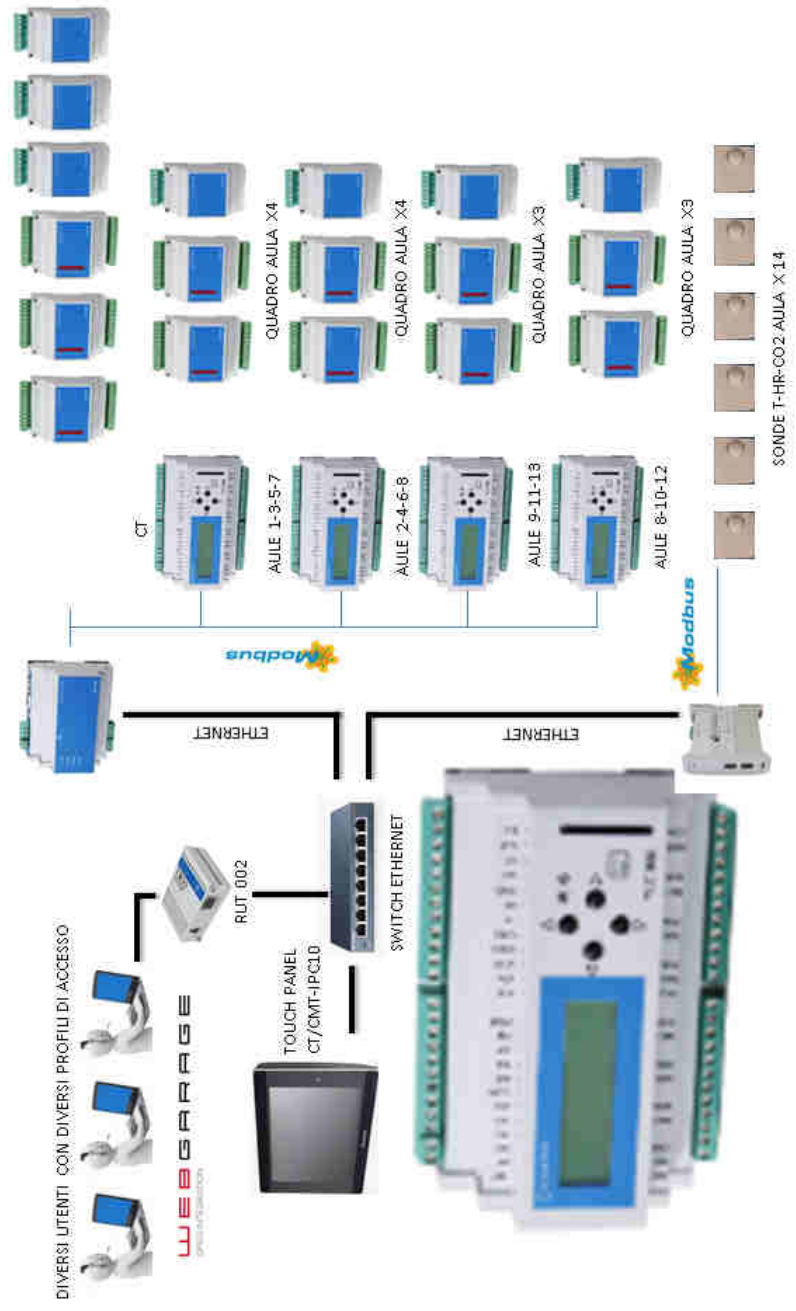

Fig. 15. diagram of BMS

Part of the BMS programming was done with the CAD mentioned earlier, some interoperability logics were programmed through the software installed on the server contained in the operator panel located in the thermal power plant. 


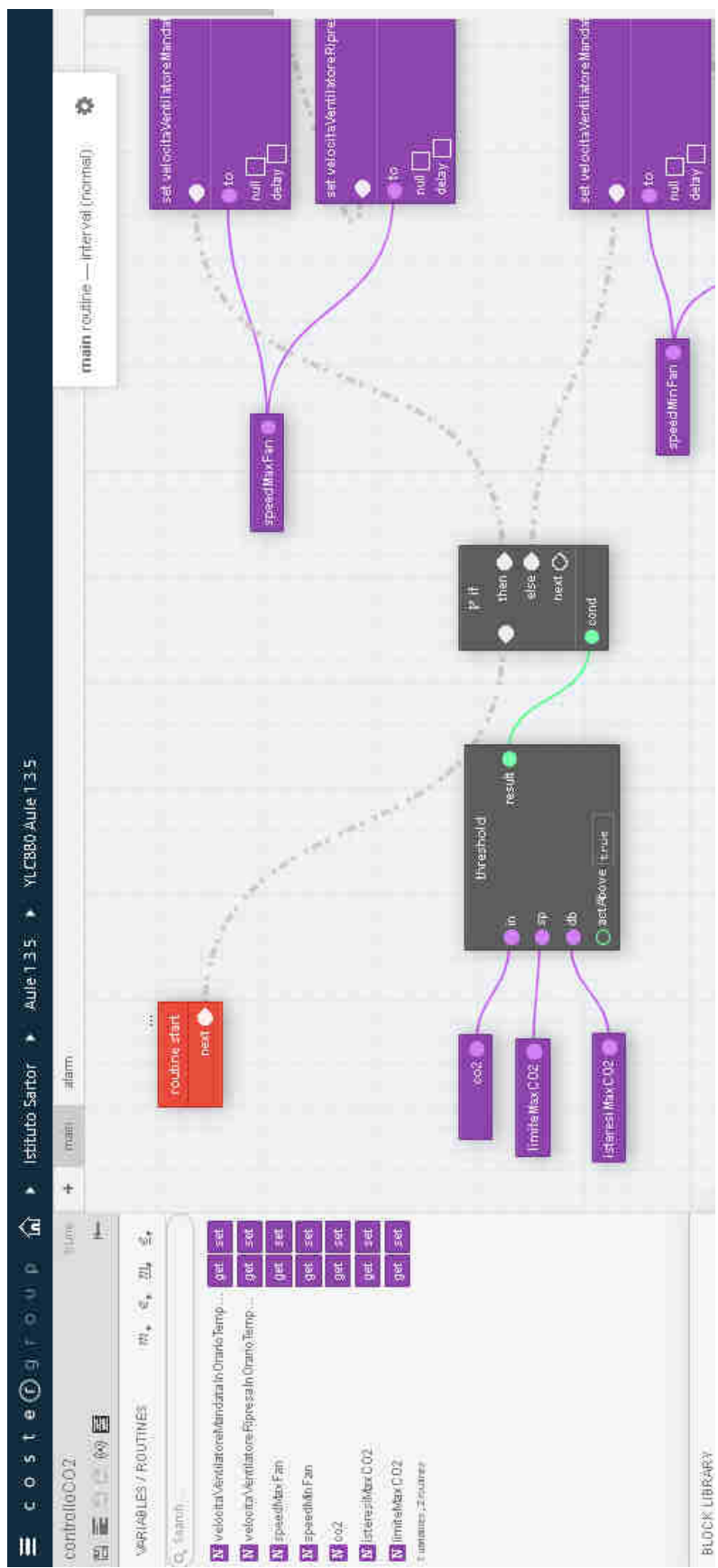

Fig. 16. Logic programmed on SCADA WebGarage to enable DCV based on IAQ

\subsubsection{Remote management}

Another fundamental aspect is the remote management of the system from the external network (internet or intranet). The SCADA in question, Webgarage, is all based on web 
platform accessible also through external networks thanks to the IP router present on the ethernet network. So remotely you can:

- check the measures in the field

- check the state of operation of the control systems

- receive alarms

- consult the loggers and view the trends of the variables

- modify the output commands in case of emergency

- verify the automation logics and in some cases modify them

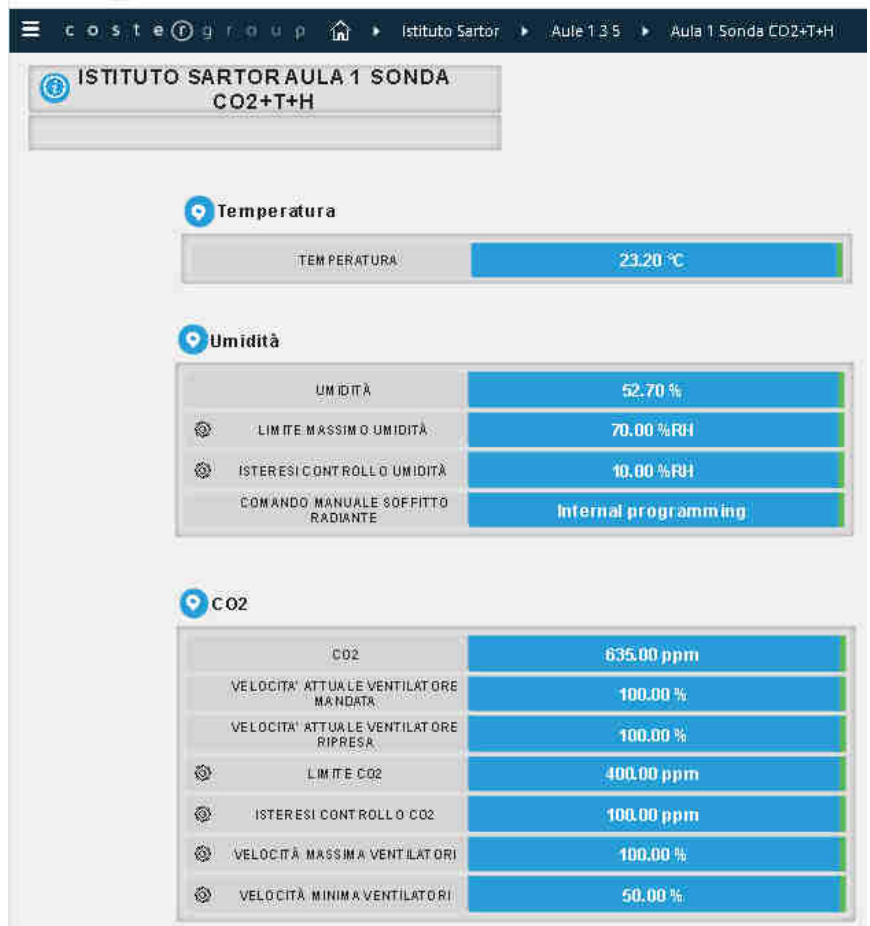

Fig. 17. Checking parameters via Web browser

\section{Future developments}

The province of Treviso has been very far-sighted. The chosen BMS is compatible with the Haystack protocol [2]. This is a data collection standard so that it is very easy and fast for other applications to access it reliably and securely (REST API). If we add this feature to the remote management mentioned earlier, you can easily understand that an external software, based on artificial intelligence and machine learning algorithms, run by the cloud, can process in real time not only this data, but potentially the data of all the other plants that have been made through the same technology and computer structure.

For example, thanks to this technology, ENEA is developing a data collection project of different flats aimed at creating a web portal that compares real consumption with theoretical consumption. They can create a reference baseline and showing similar building energy behavior to tenants, anonymously. Thanks to this information, they are enhancing competition between tenants, in order to generate a kind of "champions of energy saving". 


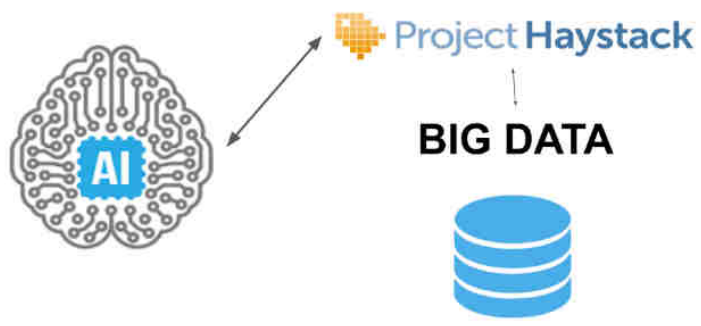

Fig. 18. Possibility of using AI and ML software with the Haystack protocol

\section{Conclusions}

The Province of Treviso, and its foresight to install the DCV in schools and a very advanced BMS system, has opened up a path which it is hoped will lead the same province to multiply this technology in other schools, but above all it is an example of how the plants in which we all live should always be built to obtain healthy and energetically efficient environments

\section{References}

1. CEN. 2017. EN 15232-1 Standard. Bruxelles: European Committee for Standardization

2. Various Authors Clusit Community for security. Intelligenza Artificiale e sicurezza. Opportunità rischi e raccomandazioni.. Page 103 .(2021) 